
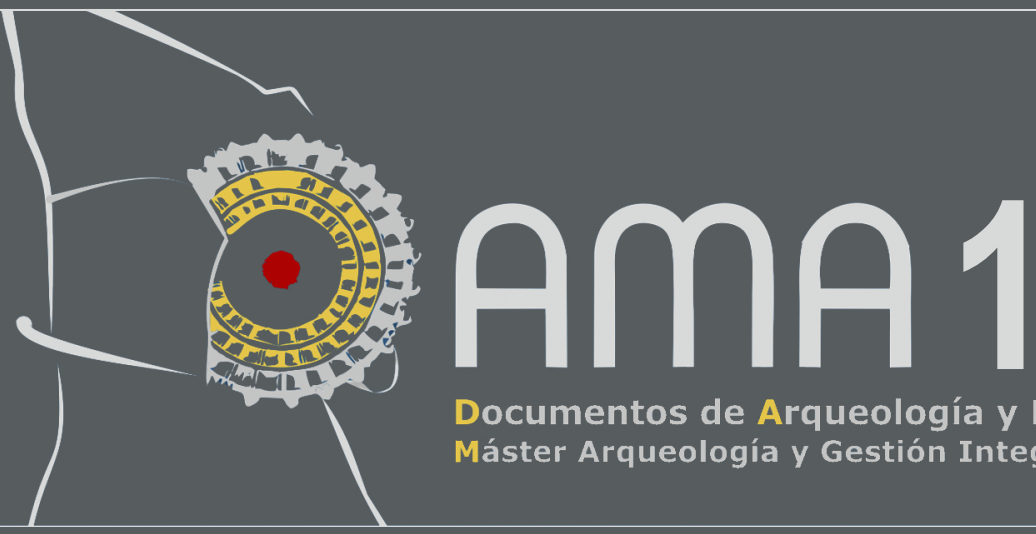

Documentos de Arqueología y Patrimonio Histórico

Máster Arqueología y Gestión Integral del Patrimonio de la Universidad de Alicante

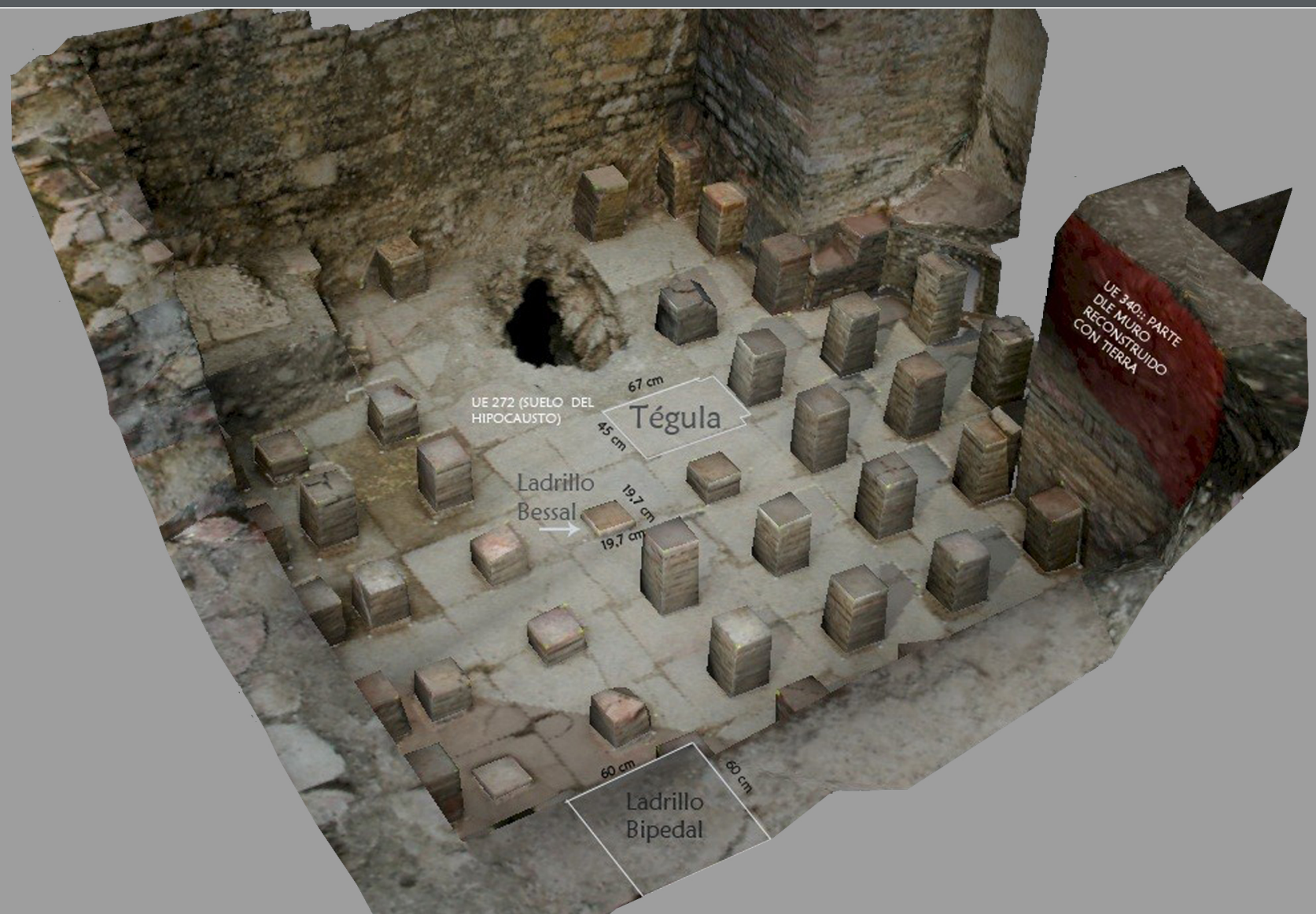

Documentos de Arqueología y Patrimonio Histórico Revista del Máster Universitario en Arqueología Profesional y Gestión integral del Patrimonio 



\section{DAMA 1}

\section{6}

DOCUMENTOS DE ARQUEOLOGÍA Y PATRIMONIO HISTÓRICO DEL MÁSTER UNIVERSITARIO EN ARQUEOLOGÍA PROFESIONAL Y GESTIÓN INTEGRAL DEL PATRIMONIO DE LA UNIVERSIDAD DE ALICANTE 


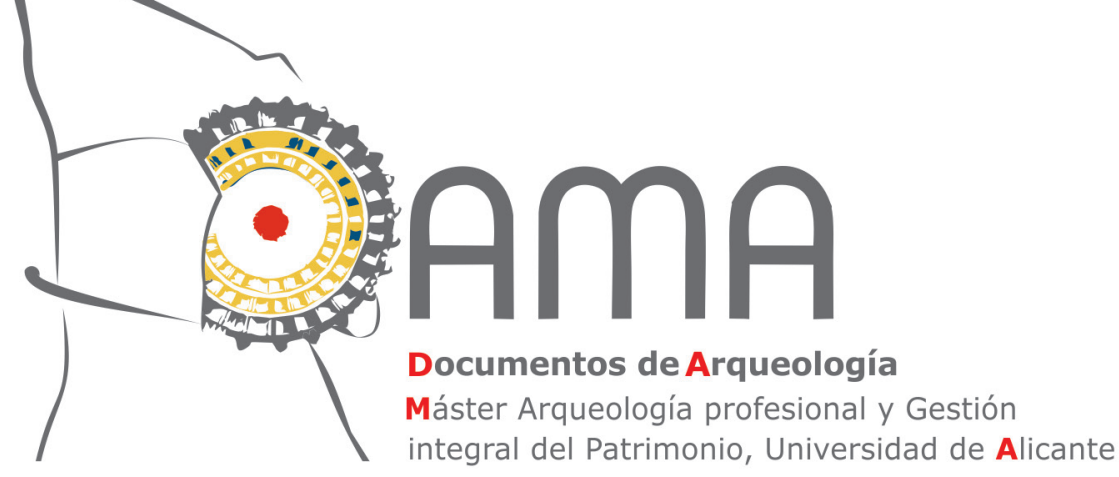

La revista electrónica DAMA. Documentos de Arqueología y Patrimonio Histórico surge como servicio para todos aquellos alumnos del Máster en Arqueología Profesional y Gestión Integral del Patrimonio de la Universidad de Alicante que se están iniciando en la investigación y cuya primera aportación a nuestra disciplina suele ser su Trabajo de Fin de Máster (TFM). Estos proyectos en muchos casos representan casi todo un curso de trabajo y esfuerzo, y con frecuencia quedan inéditos.

El objetivo de esta revista es ofrecer un medio que facilite la publicación de los resultados de sus TFM. La edición se presenta en versión digital y cuenta con su correspondiente ISSN. Se publica de forma anual en el sitio web de la Universidad de Alicante (http://web.ua.es/es/dama/) y en su repositorio (RUA). Los artículos publicados son descargables en formato PDF.

\section{Consejo de Redacción}

Directores (Coordinadores del Máster)

Carolina Doménech Belda

Fernando Prados Martínez

\section{Secretaria de Edición}

Julia Sarabia Bautista

\section{Vocales}

Los miembros de la Comisión Académica del Máster Universitario en Arqueología Profesional y Gestión del Patrimonio (http://dprha.ua.es/es/magip/comision-academica.html)

\section{Edita}

Máster Universitario en Arqueología Profesional y Gestión Integral del Patrimonio Departamento de Prehistoria, Arqueología, Historia Antigua, Filología Griega y Filología Latina

Facultad de Filosofía y Letras II

Universidad de Alicante

Ctra San Vicente del Raspeig s/n

E-03690 San Vicente del Raspeig (Alicante)

Web:http://dprha.ua.es

Teléfono: (+34) 965903663

Fax: (+34) 965903823

E-mail: revista.dama@ua.es

\section{ISSN}

$2530-2345$

\section{Portada}

Modelo fotogramétrico de un hypocaustum romano realizado por Ana Charquero 
EDITORIAL

Coordinación del máster

ENTREVISTA A SOLVEIG NORDSTRÖM: UNA MIRADA HACIA EL PASADO DE LA ESCUERA

Raúl Berenguer González ..

\section{ARQUEOLOGÍA Y MÉTODO}

EL ESTUDIO DE LOS MATERIALES CONSTRUCTIVOS DE TIERRA DEL CABEZO DEL POLOVAR (VILLENA, ALICANTE): APORTACIÓN A LAS FORMAS CONSTRUCTIVAS DE DOS PEQUEÑAS EDIFICACIONES CAMPESINAS DE LA EDAD DEL BRONCE EN EL LEVANTE PENINSULAR

María Pastor Quiles

VIVIENDAS POSTALAYÓTICAS: UNA APROXIMACIÓN A LOS ESPACIOS DOMÉSTICOS EN EL ARCHIPIÉLAGO BALEAR (550-123 ANE)

Octavio Torres Gomáriz

LAS FLOTAS DE GUARNICIÓN ROMANA EN LAS COSTAS DE HISPANIA A PARTIR DE LAS FUENTES EPIGRÁFICAS

Sergio Lledó Ramírez

UNA APROXIMACIÓN A LA RECONSTRUCCIÓN DEL PAISAJE HISTÓRICO: EL PROYECTO L'ALMISSERÀ Diana López Arroyo

NUEVAS PERSPECTIVAS PARA EL ESTUDIO ARQUEOLÓGICO DEL POBLAMIENTO RURAL MEDIEVAL EN ASPE (ALICANTE): HUERTAS Y ALQUERÍAS JUNTO AL RÍO TARAFA

Felipe Mejías López

ARQUEOLOGÍA DE LAS GUERRAS CARLISTAS

Iván Roldán Vergarachea

LA CERÁMICA DE USO ARQUITECTÓNICO EN NOVELDA: LA AZULEJERÍA DE FINALES DEL SIGLO XIX Y PRINCIPIOS DEL XX

Natalia Sala Pérez

PRÁCTICA Y USOS DE LA FOTOGRAMETRÍA DIGITAL EN ARQUEOLOGÍA

Ana $M^{a}$ Charquero Ballester.

\section{GESTIÓN Y PUESTA EN VALOR DEL PATRIMONIO}

ARQUEÓLOGOS CON DISCAPACIDAD. ARQUEOLOGÍA INCLUSIVA

Ana Samaniego Espinosa

"LES COVES DELS PESCADORS DE EL CAMPELLO": PROPUESTA DE RECUPERACIÓN, PUESTA EN VALOR Y USO PÚBLICO DE UN PATRIMONIO OLVIDADO

Ana Isabel Castro Carbonell .

LA COLONIA DE SANTA EULALIA. ESTUDIO Y PROPUESTA DE RECUPERACIÓN

Héctor de Arriba González

PROYECTO DE PUESTA EN VALOR DE LOS RESTOS DE LA GUERRA CIVIL EN LA CIUDAD DE ALICANTE

Leticia Victoria González Chouciño

ANTEPROYECTO MUSEOGRÁFICO DEL MUSEO DE HISTORIA DE SAX

Alberto Ochoa García

EL CONGRESO DE MÁSTER: UNA PROPUESTA DIDÁCTICA DEL MÁSTER DE ARQUEOLOGÍA DE LA UNIVERSIDAD DE ALICANTE

Ignasi Grau Mira, Sonia Gutiérrez Lloret, Carolina Doménech Belda, Julia Sarabia Bautista 



\title{
UNA APROXIMACIÓN A LA RECONSTRUCCIÓN DEL PAISAJE HISTÓRICO: EL PROYECTO L'ALMISSERÀ.
}

\author{
Diana López Arroyo
}

\section{RESUMEN}

En el presente trabajo se plantea abordar una aproximación a la reconstrucción del paisaje histórico en torno a un espacio agrícola rural. Partiendo de los preceptos establecidos por la Arqueología del Paisaje y la Arqueología agraria, se pretende emplear la metodología de los SIG a un paisaje histórico para llevar a cabo una lectura social del mismo, aunando el estudio del hábitaty el territorio. Incluyendo, además, el uso de la toponimia, la documentación histórica y el análisis cartográfico. Con todo ello, se pretende caracterizar el paisaje agrario de la alquería, su evolución y su organización, esbozando las funciones establecidas para cada yacimiento mediante el estudio de sus características internas y del territorio que les rodea; tratando de conocer aspectos de la economía, el control territorial o el sistema de explotación de los recursos, mediante el análisis de parámetros como la accesibilidad, situación geográfica y/o la visibilidad.

Palabras claves: Arqueología Medieval, Arqueología del Paisaje, espacios agrarios, Sistemas de Información Geográfica, alquería.

\section{ABSTRACT}

In the following paper a reconstruction of the historical landscape around the rural agrarian space. Thus, and from the bases laid out by Landscape Archaeology and Agrarian Archaeology, a GIS methodology will be applied to a historical landscape in order to obtain a social reading from it, putting together both the studies of habitat and territory. This will be further complimented by the study of toponims, historical documents and cartographic analyses. All in all, it will be possible to characterise the agrarian landscape formed by the alquería, its evolution and organisation, outlining the diverse functions ascribed to each individual site according to their internal characteristics and surrounding territory, further researching into their economy, their control over the territory and the various resource exploitation systems according to the analysis of certain parameters such as accessibility, location and/or visibility.

Key words: Medieval Archaeology, Landscape Archaeology, agrarian space, Geographic Information System, alquería. 


\section{A MODO DE PROLEGÓMENO}

El presente trabajo se planteó en el marco del máster universitario en Arqueología profesional y gestión del patrimonio cursado entre 2012-2013. Dicho estudio supuso el inicio de una línea de investigación en la que existía la pretensión de abordar el estudio del espacio agrícola y la reconstrucción del paisaje histórico en torno a un poblamiento rural andalusí. Concretamente, la investigación del Trabajo Fin de Máster (TFM) se centró en torno a una serie de alquerías de época islámica localizadas en la partida rural conocida como L'Almisserà (Villajoyosa, Alicante). Toda la investigación, se encontraba inmersa en el marco del "Proyecto L'Almisserà1"; al cual debo agradecer toda la ayuda prestada por parte del equipo investigador y, en especial, por la gentileza de facilitarme información al respecto de los enclaves: memorias de excavación, planos de los yacimientos, fotografías de los mismos, etc.

El "Proyecto L'Almisserà" constituyó el comienzo de una línea de investigación y un hito importante para la Marina Baixa. Es común referirse a esta comarca como una gran desconocida de la arqueología alicantina; en relación a otras comarcas, y muy especialmente, en cuanto al poblamiento andalusí se refiere. Con esta investigación surgida a tenor del proyecto, se pretendía constituir en un futuro un referente más para profundizar en el estudio del sistema del poblamiento rural islámico en tierras del Šarq al-Andalus.

La importancia de este conjunto radica en el hecho de contar con tres alquerías excavadas íntegramente en la Comunidad Valenciana, además del hallazgo de una de las escasas mezquitas rurales halladas en el territorio valenciano (Calvo, 2014, p. 502). Estos yacimientos ofrecen la posibilidad única de estudiar un sistema de poblamiento donde se integran perfectamente lugares de hábitat (alquerías), de culto (mezquita y necrópolis) y quizá de control territorial (atalaya) en una cronología que engloba, al menos, cuatro siglos de ocupación musulmana (siglos X-XIII). Sin embargo, el hallazgo más relevante es sin duda el propio conjunto, pues éste nos proporciona datos a nivel organizativo y de sus relaciones externas.

\section{EL MEDIO GEOGRÁFICO}

El territorio objeto de nuestro estudio se localiza en la partida denominada L'Almisserà en el término municipal de Villajoyosa en la comarca de la Marina Baixa ${ }^{2}$ (Fig. 1), al norte de la provincia de Alicante (España). Se trata de una comarca costera, pero de relieve accidentado, muy montañosa, pues pertenece a las cordilleras del Sistema Subbético- el borde norte de las estribaciones béticas ${ }^{3}$ peninsulares- y, dentro de éste al Prebético (Galiana, 2001, pp. 12-29). Concretamente, en la comarca se observan elevaciones que alcanzan los más de $1000 \mathrm{msnm}$. Estas prominencias ocupan una posición central y dividen la comarca en dos cuencas principales: la del río de la Vila (Amadorio) al Oeste y la del río de l'Argar al Este. Entre las altas sierras se disponen algunos valles estrechos de pendientes uniformes que están dirigidos principalmente de noreste al suroeste, y escalonados hacía el sureste (Ministerio de agricultura, 1981, p. 10). No se contemplan lugares de marjal, ni albuferas

1 Este proyecto se inició gracias a la nueva identidad corporativa de la Sección municipal de Arqueología, Etnografía y Museos de La Vila Joiosa, VilaMuseu, dentro de la Concejalía de Patrimonio Histórico, con una serie de prospecciones en 2001 por parte de la empresa Archeos, bajo la dirección de Jose Ramón García Gandía. Posteriormente, se realizaron excavaciones arqueológicas durante los años 2002-2003.

2 La comarca limita al noreste con la de la Marina Alta, al noroeste con las comarcas de El Comtat y L'Alcoià, al suroeste con la comarca de L'Alacantí y al sur con el mar Mediterráneo. Esta comarca comprende los actuales términos municipales de Villajoyosa, Orxeta, Relleu, Sella, Finestrat, Benidorm, L’Alfas del Pí, La Nucía, Polop, Benimantell, Benifato, Confrides, Beniardá, Guadalest, Callosa d'en Sarriá, Altea, Bolulla y Taberna.

3 Justo cuando este borde suboriental del extremo norte de la Sierra Bética se hunde en el mar para continuar más allá en las islas Baleares (Galiana, 2001, p. 32). 


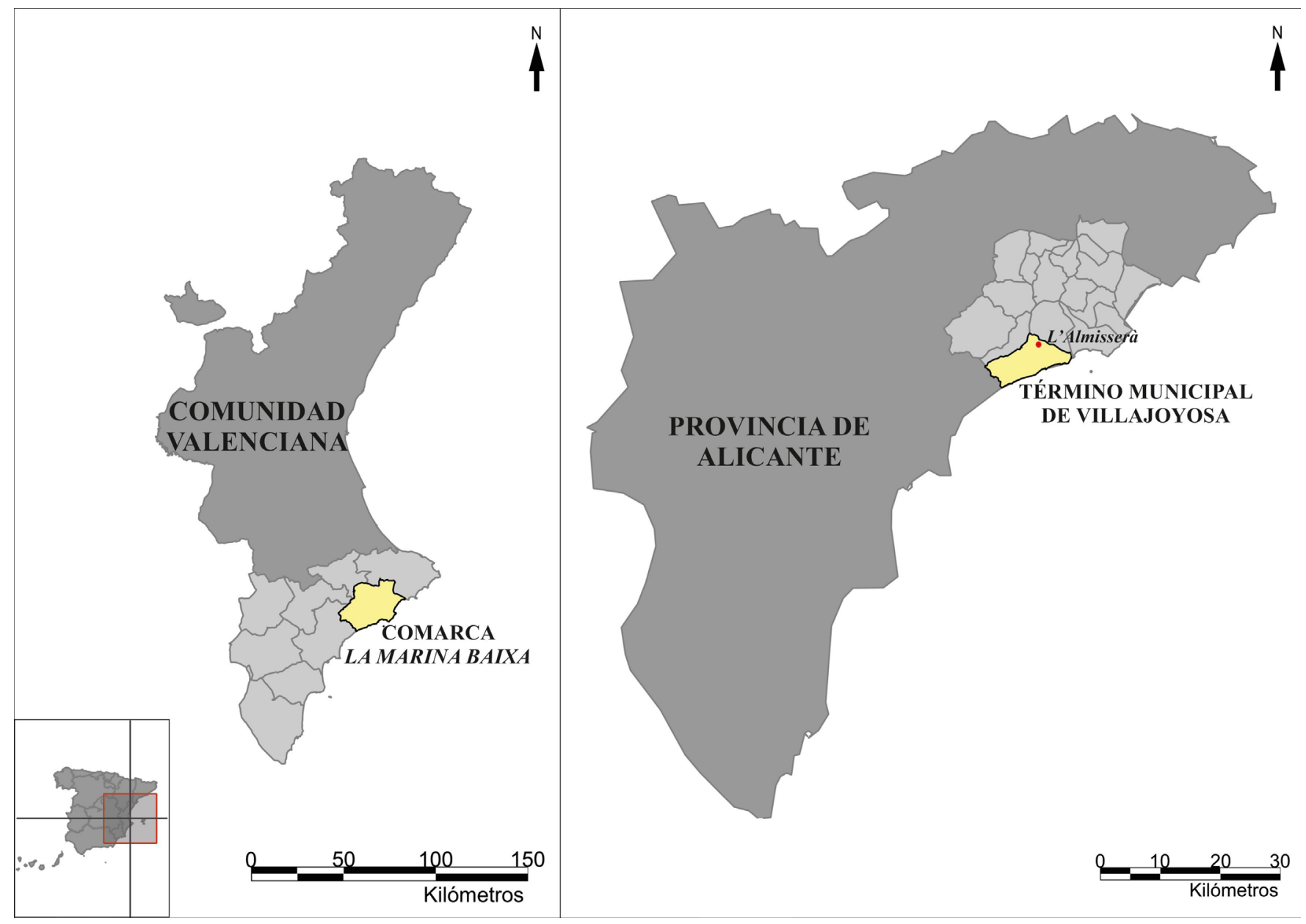

Fig. 1. Localización del término municipal de Villajoyosa en la comarca de la Marina Baixa en la provincia de Alicante (Fuente: Institut Cartogràfic Valencià) [Elaboración propia].

de gran extensión debido a la ausencia de grandes planicies (Galiana, 2011a, p. 52), como sí sucede en el resto del litoral valenciano.

En general, dado al carácter montañoso de la comarca, la red fluvial aparece diversificada y muy ramificada (Ministerio de agricultura, 1981, p. 14), por lo que en esta comarca son considerados ríos propios el río Amadorio, el río Argar, el río Torres y Aigües.

Concretamente, en cuanto al término municipal de Villajoyosa, se considera un altiplano formado por las aportaciones fluviales cuaternarias (Galiana, 2011a, p. 52) utilizadas durante gran parte de la historia para la huerta entre los dos ríos que la rodean, los ríos Amadorio y el Torres. El área de estudio quedaría integrada en el corredor de entrada al pequeño valle de Finestrat y, aunque se encuentra en la zona limítrofe de este término al Norte y al Este, pertenece al término municipal de Villajoyosa (Fig. 2). Al Sur está delimitada por la autopista A7 y al Oeste por la carretera comarcal que une Villajoyosa con Finestrat. La partida está circundada por dos ramblas ${ }^{4}$ que discurren por el perímetro de la partida formando una porción de tierra fértil para el cultivo y rica en recursos hídricos. Los terrenos de la partida son de ligera pendiente con pequeñas elevaciones. Su acceso se realiza mediante la carretera comarcal que une Villajoyosa con Finestrat, a la altura del kilómetro cinco. La altitud máxima de la partida versa en torno los $153 \mathrm{msnm}$ y la mínima aproximadamente los 64 msnm (García et al., 2001, p. 126).

4 Son corrientes fluviales con poco caudal y discontinuos que transportan agua tras registrarse fuertes precipitaciones. 


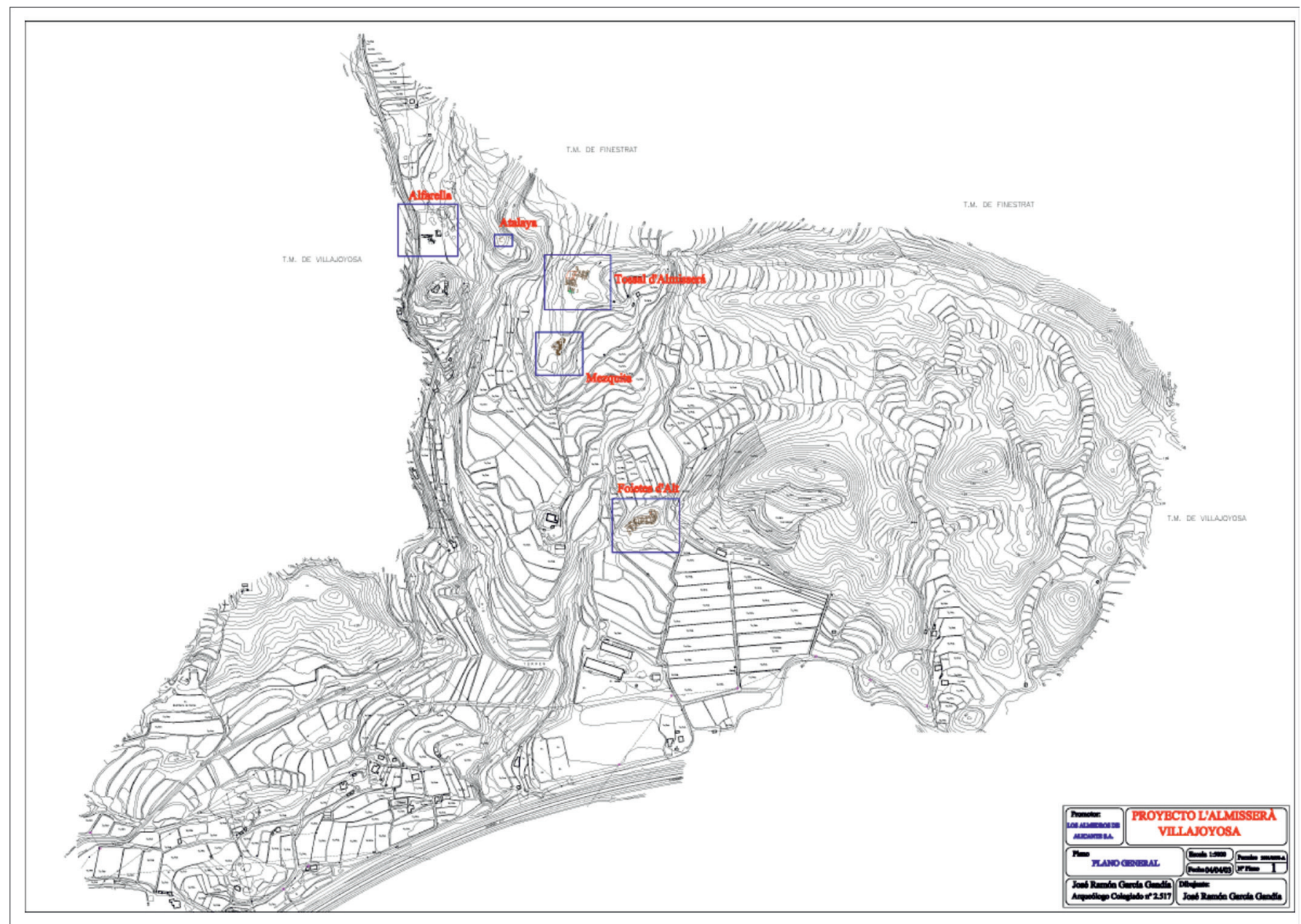

Fig. 2. Plano general de la situación de los yacimientos de L'Almisserà (Plano cedido por Jose Ramón García Gandía).

\section{ALMISSERANS. EL POBLAMIENTO RURAL ISLÁMICO}

\section{1. Descubrimiento e Historia de la investigación}

La importancia arqueológica de esta zona es conocida desde antiguo. Ya hay una mención de Pascual Madoz en 1845 al respecto de un hallazgo romano (Madoz, 1845, p. 158). No obstante, el primer inventario por escrito de estos yacimientos con adscripción islámica se dio entre la década de los ochenta y los noventa del siglo XX a raíz de una beca de investigación "Juan Gil-Albert" concedida a Antonio Espinosa Ruiz ${ }^{5}$ (Espinosa, 1987, pp. 160-162). En ella expone de forma breve, pero precisa, las características de los restos visibles en dicha partida, estableciendo su adscripción islámica de comienzos del siglo XIII. Antonio Espinosa plantea que eran totalmente desconocidos hasta la fecha y que aparentemente no habían sido expoliados, pero si modificados o destruidos a causa de abancalamientos contemporáneos.

Desde entonces se han publicado varias referencias sobre la partida y los yacimientos que abarca. En primer lugar, en 2001 se publicó un avance de las prospecciones en la revista del Museo de Alcoy. Se trataba de una primera aproximación con resultados provisionales y el planteamiento de hipótesis y objetivos a resolver en posteriores investigaciones (García et al., 2001, pp. 125-134). Posteriormente,

5 Se carece de información precisa al respecto del descubrimiento de estos yacimientos, aunque parece que uno de los primeros conocedores de estos enclaves fue José Payá Nicolau (Espinosa, 1990, p. 431). 
en 2003, tras haberse realizado las excavaciones durante 2002-2003, se presentaron los resultados en las II Jornadas de Arqueología Medieval. De la Medina a la Vila (García, Llorens y Pérez, 2004, pp. 83105). Finalmente, José Ramón Gandía presentó los resultados obtenidos de las excavaciones en las 1as Jornadas sobre la Actualidad del Patrimonio Arqueológico y Etnográfico de la Marina Baixa (García, 2005, pp. 9-15). Estas publicaciones dan cuenta de los trabajos emprendidos como consecuencia de una actuación urbanística que se iba a ejecutar en la partida L’Almisserà que pretendía la construcción de instalaciones deportivas, un complejo hotelero y una urbanización.

\section{2. Encuadre cronológico-cultural}

Como ya se ha señalado, los yacimientos de L'Almisserà se encuadran en la cultura islámica y corresponden al ámbito rural. Se trata de enclaves cuya funcionalidad sería la explotación agropecuaria del territorio.

En la comarca de la Marina Baixa son escasos los restos entre los siglos VIII-IX d.C. (Espinosa, 2011, p. 215). El asentamiento e instalación tardía de musulmanes en la zona fue consecuencia de un despoblamiento generalizado en el área desde época tardorromana. Claro ejemplo es nuestro caso de estudio, donde los primeros vestigios de población andalusí se encuentran en Foietes de d'Alt, cuyos niveles de abandono han sido fijados en el siglo XI (García et al., 2005, p. 10), es decir, en plena época taifa.

La titubeante estructura del poblamiento islámico hasta finales del siglo X, adquirió una sólida configuración con la llegada del siglo XI, apreciable en la uniformidad y normalización de su cultura material que afectó a todas sus manifestaciones (Gutiérrez, 2004, 2007, 2011, 2012b). Como consecuencia de la descomposición del Califato de Córdoba, se asistió a la formación de los reinos de taifas, donde nuestra zona de estudio quedaría englobada bajo el dominio de la Taifa de Denia (Azuar, 1989, pp. 13-31).

Entre finales del siglo XI y primera mitad del siglo XII se produce el despoblamiento de algunos lugares, como parece ser en el caso Foietes de d'Alt. Parece observarse una dinámica de reestructuración del poblamiento en la que se asiste a un masivo crecimiento de los núcleos urbanos en detrimento de los establecimientos rurales (Azuar, 1994, p. 245).

En la segunda mitad del siglo XII -Imperio almohade- hasta la conquista cristiana se asiste a un aumento poblacional tanto en las zonas históricas del área del norte de Alicante, como en otras zonas que hasta el momento estaban deshabitadas o escasamente pobladas como serán los valles de Finestrat y Guadalest ${ }^{7}$. Estas poblaciones generan asentamientos de nueva planta; quizás las alquerías del Tossal de L'Almisserà y l'Alfarella podrían incluirse en esta dinámica de repoblación y dinamización de las áreas agrícolas como veremos a continuación ${ }^{8}$.

\footnotetext{
6 Dichos yacimientos se encuentran catalogados en el Catálogo de Bienes y Espacios protegidos del PGOU de Villajoyosa y con ficha en el Inventario Inmueble de la Dirección General de Patrimonio Cultural Valenciano que depende de la Consellería de Cultura y Educación de la Generalitat Valenciana <http://www.cult.gva.es/dgpa/index c.html >.

7 El valle de Guadalest albergaría desde ese momento a la mayor parte de la población hasta época morisca. Orxeta pasaría a ser el principal núcleo urbano de la zona y la costa se encontraría poco poblada (Galiana, 2001, pp. 101-102). 8 El estudio de la morfología doméstica y urbanística de estas alquerías se ha abordado en el proyecto HAR2012-34035 "Lectura arqueológica del uso social del espacio. Espacios domésticos y vida social entre la Antigüedad y el Medievo" del MINECO, del que formo parte, mientras que la relación de los ajuares con los espacios construidos se aborda en el marco del nuevo proyecto HAR2015-67111-P "El sitio de las cosas: relación entre la cultura material y los espacios construidos a la luz de la arqueología (siglos VI-XIV)”, del MINECO, en cuyo equipo me integro.
} 
Es en esta época cuando la actual Marina Baixa funciona como frontera entre el Imperio almohade y la Corona de Aragón, y, al igual que el resto de las zonas meridionales de la Comunidad Valenciana, sufre una época de inestabilidad política (Guichard, 2001, pp. 633-634). Con la entrada de las tropas de Jaime I en Valencia, se desencadena un proceso de desmembramiento del régimen político al que estaban sujetas las alquerías. Los territorios se anexionan a la Corona de Aragón y se implanta un nuevo régimen de posesión de tierras.

\section{3. Foietes de Dalt}

Se trata de una pequeña alquería encaramada en un cerro agreste y estrecho que se abre a una amplia vega que desemboca en el mar (García, Llorens y Pérez, 2005, p. 10). Su inicio se ha fijado en torno a mediados del siglo IX d.C. y su abandono hacía mediados del siglo XI d.C., sin que se haya determinado con certeza la razón de dicho abandono (García, Llorens y Pérez, 2004, p. 90). No obstante, se plantea como hipótesis que se produzca y sea consecuencia, a la par, de la inestabilidad política vivida en este periodo. Otra hipótesis que baraja el equipo de investigación del proyecto es la posibilidad de que la población de Foietes se desplace a las nuevas alquerías de L'Alfarella y Tossal de L'Almisserà. Sin embargo, la relación que pudieran tener los habitantes de Foietes con la génesis de alguna de las nuevas alquerías está por estudiar y determinar.

Se pueden intuir los criterios seleccionados a la hora de escoger el terreno para emplazar esta alquería. Cuenta con una visibilidad óptima de la vega al sur hasta avistar el mar, así como del norte hasta el Puig Campana. Además, a poco más de 300 metros discurre el cauce del río Torres.

El estado de conservación de las estructuras es bastante deficiente como resultado del efecto erosivo de los agentes naturales sobre estructuras cimentadas directamente sobre el suelo rocoso, pero permite reconocer su planta y estructura.

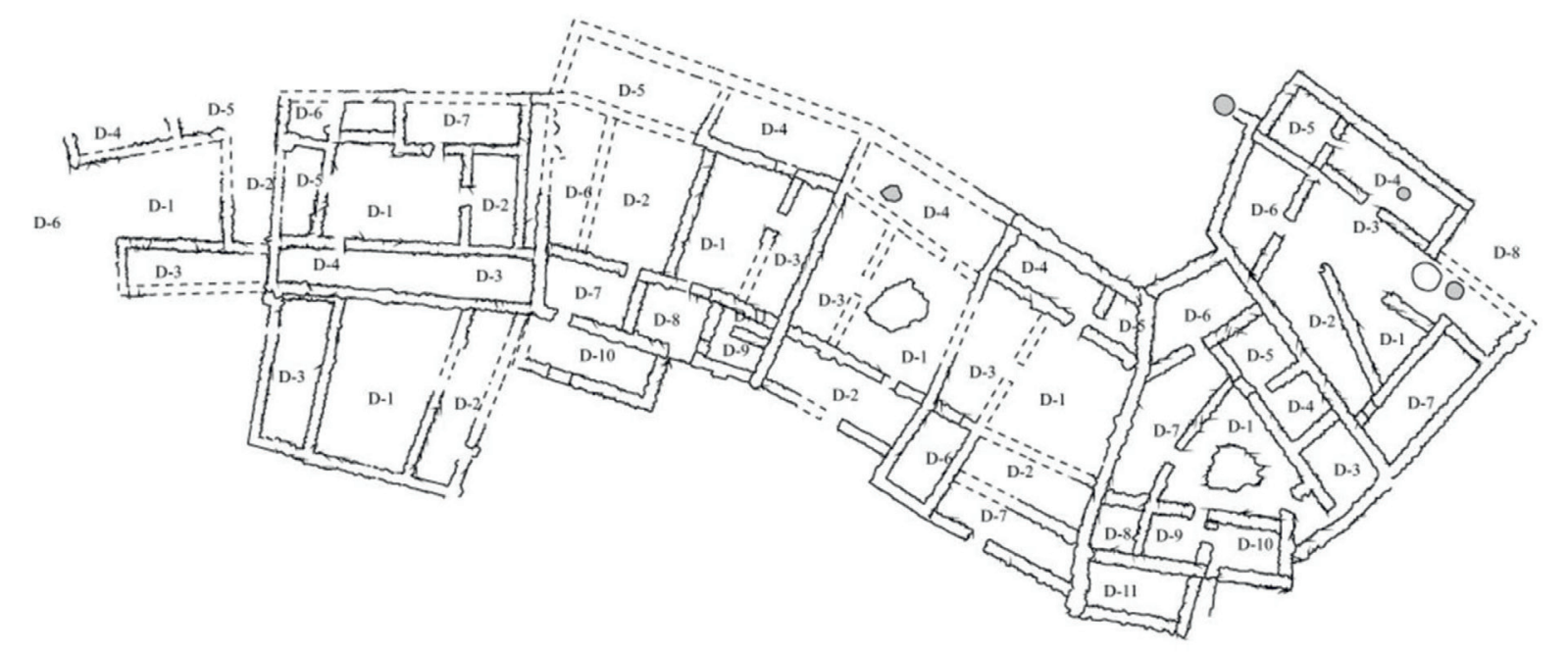

Fig. 3. Plano de la Foietes de d'Alt (García, Llorens y Pérez, 2004, p. 90). 
Parece tratarse de un asentamiento creado ex novo, con una sola fase constructiva (García, Llorens y Pérez, 2004, p. 91). El total de casas documentadas son nueve (Fig. 3). Las casas se disponen apoyándose unas sobre otras en una sinuosa línea que se adapta perfectamente a la superficie del promontorio, logrando el máximo aprovechamiento del espacio disponible (García, Llorens y Pérez, 2004, p. 91). El tipo de casa ya responde al modelo de "casa de patio", es decir unidades complejas estructuradas en torno a un patio, que es el eje vertebrador de la misma y da paso a las diferentes estancias (Gutiérrez, 2012a, pp. 147-8). Presentan una organización espacial colindante alineada, no demasiado usual pero condicionada en este caso por la topografía (Gutiérrez, 2012a, pp. 157-158; 2015, pp. 26-27).

\section{4. Tossal de L'Almisserà}

Se trata de un asentamiento que se dispone en un cerro amesetado (García et al., 2001, p. 130). En base a los repertorios cerámicos, se ha podido establecer un horizonte cronológico comprendido entre el siglo XII d.C. hasta mediados del siglo XIII d.C., en un contexto cultural claramente almohade (García, Llorens y Pérez, 2004, p. 86).

Su escasa altura no parece jugar un papel determinante en la elección del emplazamiento, por lo que el criterio de defensa no parece ser primordial. Si lo serían su amplio dominio visual del territorio

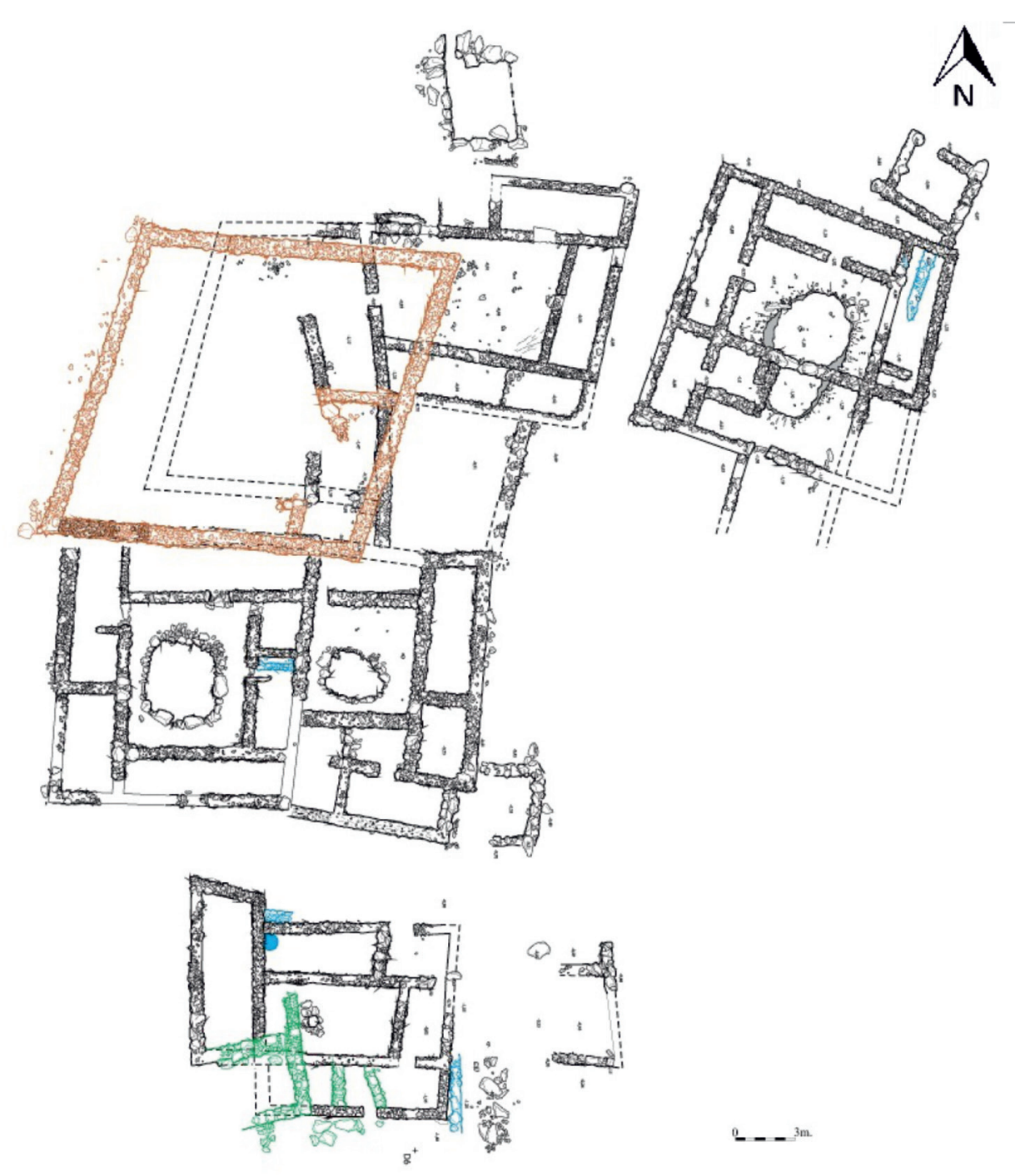

Fig. 4. Plano del Tossal de L'Almisserà (García, Llorens y Pérez, 2004, 85). circundante y la cercanía a los cursos de agua, como el río Torres.

Se documentaron un total de seis unidades habitacionales y cinco estructuras menores que parecen corresponder a una misma fase constructiva (Fig. 4), fechada en los siglos previos a la conquista cristiana (siglos XII-XIII d.C.) (García, Llorens y Pérez, 2005, p. 10). Estás parecían organizarse en un modelo de organización agrupada, de forma que las viviendas, aisladas o colindantes, establecen una relación basada en la proximidad (Gutiérrez, 2012a, pp. 156-157), definiendo intersticios entre ellas que parecen definir calles o ejes de circulación de norte sur y de este a oeste. Las plantas corresponden al esquema clásico de la casa islámica 
andalusí "de patio" y al igual que en el resto de las alquerías las crujías se disponen longitudinalmente, siendo frecuente la presencia de alcorques centrales (Gutiérrez, 2015, pp. 23-25). Cabría señalar que en dos casos, las viviendas se hallan aisladas, mientras que el resto colindan conformando una manzana.

Además, se constató la existencia de una fase bajomedieval, siglos XIV-XV d.C., con un nuevo edificio de mayores dimensiones, correspondiente quizá a un corral.

Se desconocen las causas de su abandono, pues arqueológicamente no se documentó un final violento, brusco o súbito, pero debió vincularse a la nueva reestructuración del territorio como consecuencia de la conquista cristiana.

\section{5. L'Alfarella}

Esta vez la alquería se ubica en el llano, a diferencia de las anteriores. Los materiales hallados sugieren una ocupación que va desde mediados del siglo XII d.C. hasta mediados del siglo XIII d.C., en plena época almohade (García, Llorens y Pérez, 2004, p. 95).

No parece que la selección del emplazamiento respondiese con la visibilidad del entorno o la buena posición defensiva, puesto que la situación en un llano con pequeños relieves a su alrededor limita el campo de visión. No obstante, cerca de la alquería y en altura, se encuentra una estructura cuadrangular que podría asumir las funciones de defensa y control territorial (La Atalaya). El criterio primordial de este emplazamiento parece ser la explotación agrícola y la proximidad al río Torres.

Actualmente, subsisten escasos restos, de poca consistencia y muy arrasados como consecuencia de la intensa actividad agrícola. No obstante, se documentaron cuatro casas (Fig. 5) cuyos contextos cerámicos de abandono se datan en un momento avanzado del siglo XIII d.C. (García, Llorens y Pérez, 2005, p. 11)

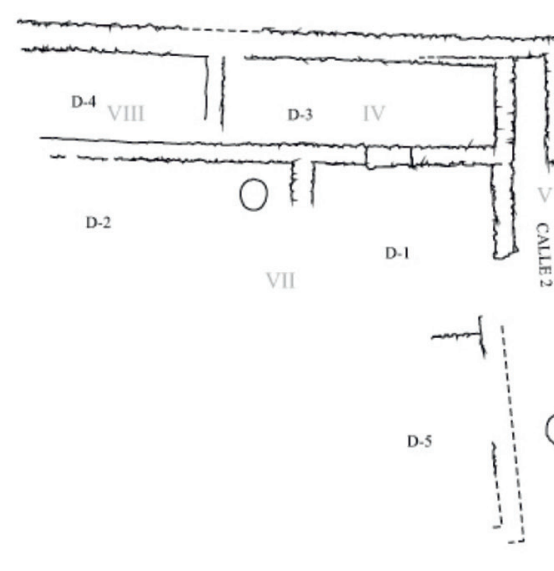

CASA 2
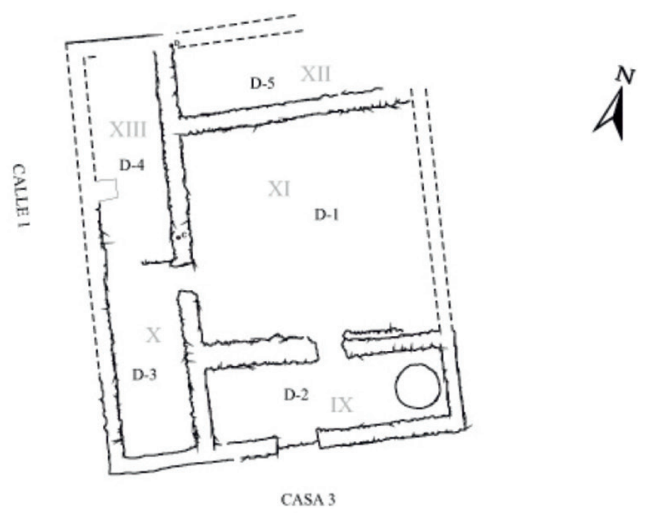

Fig. 5. Plano de L’Alfarella (García, Llorens y Pérez, 2004, p. 95). 
En cuanto a la configuración interna, por el deficiente estado de los restos, las interpretaciones son hipotéticas. Se pueden apreciar todavía los límites de las casas con planta de tendencia cuadrangular alineadas y separadas por estrechos espacios perpendiculares que, en base a sus dimensiones y a la falta de compartimentación interna, se identificaron como calles (García, Llorens y Pérez, 2004, p. 97). En cuanto a la distribución interna de los espacios habitacionales nos encontramos de nuevo con el esquema habitual de un patio central descubierto de tendencia cuadrangular que da acceso a las diferentes dependencias (Bazzana, 1990, 249-253; 1992, pp. 161-200). Se trata del mismo esquema constructivo que en el resto de alquerías y que hemos de suponer ya plenamente consolidado en el medio rural a partir del siglo XI (Gutiérrez, 2011, pp. 197, 199; 2012, pp. 46-51)

\section{6. Mezquita y necrópolis}

Uno de los grandes hallazgos de las excavaciones fue la exhumación de uno de los pocos ejemplos de mezquita rural documentada en Šarq al-Andalus, con un espacio funerario asociado (Fig. 6).

$\mathrm{Su}$ emplazamiento se encuentra en una pequeña elevación natural, en un punto aproximadamente intermedio entre las tres alquerías identificadas. El equipo de excavación planteó la posibilidad de encontrarse ante una mezquita aljama, por su situación, dimensiones y tipología (Calvo, 2014, p. 949; García, Llorens y Pérez, 2005, pp. 13-14). Las hipótesis que se barajan es que la mezquita fue construida en el siglo XI d.C. y en una segunda fase perdería el carácter religioso para adquirir la zona el ámbito funerario (Calvo, 2014, p. 495; Espinosa, 2011, p. 216; García, Llorens y Pérez, 2004, pp. 99-100)

Se trata de un espacio de culto y religioso y, a la vez, funerario, pues en los alrededores se documentaron un total de 79 tumbas $^{9}$ (García, Llorens y Pérez, 2004, pp. 101-103).

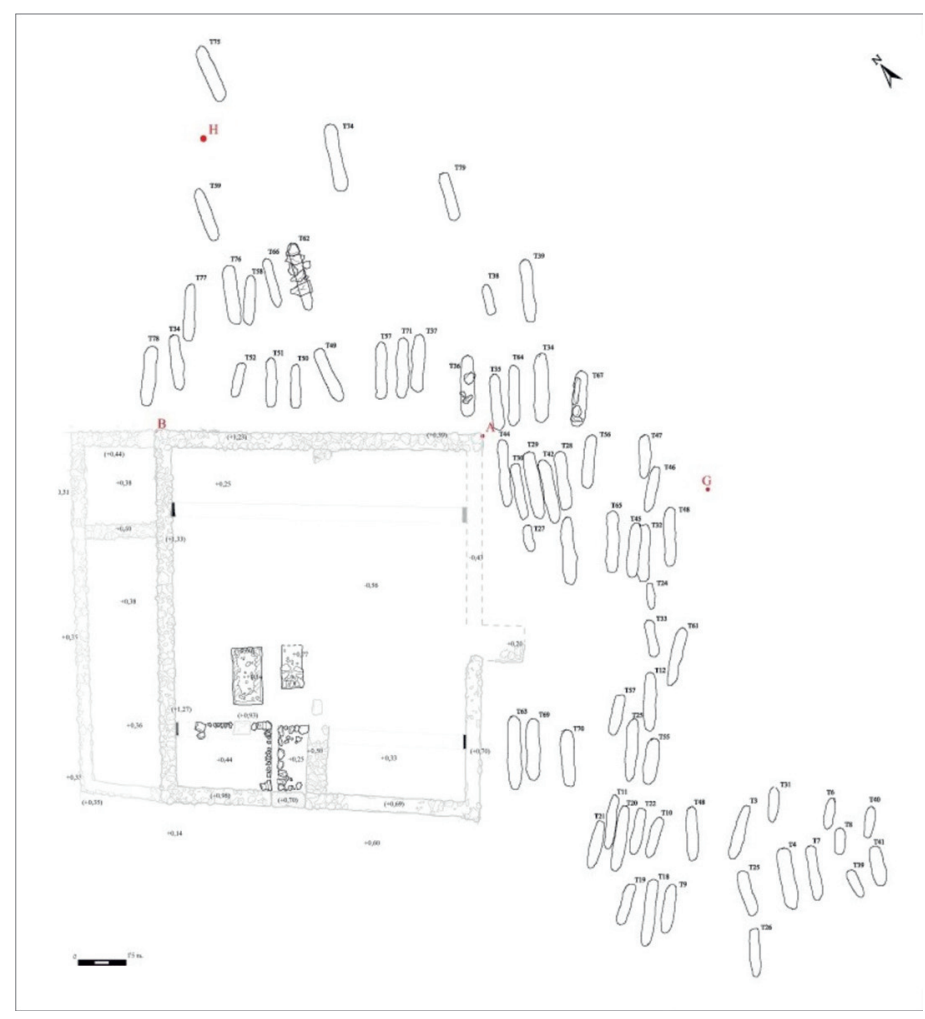

Fig. 6. Planos de la mezquita y la necrópolis (Plano cedido por Jose Ramón García Gandía).

\section{7. Atalaya}

Se trata de una estructura cuya planta se adivina cuadrangular. Está localizada en la cota más alta de un cerro amesetado a una distancia de doscientos metros en línea recta del Tossal de L'Almisserà en su lado oeste. Por el material encontrado, su cronología se estableció entre los siglos X d.C., en época califal, y mediados del siglo XII d.C. (García, Llorens, Pérez, 2003, p. 35). No se ha podido precisar una cronología más específica y/o fiable a causa de los insuficientes testimonios materiales.

9 En la actualidad el equipo del proyecto HAR2015-67111-P "El sitio de las cosas: Relación entre la cultura material y los espacios construidos a la luz de la arqueología (ss. VI-XIV)" tiene prevista una intervención puntual para determinar su origen y eventual carácter funerario. 
Tanto por la estructura como por su posición, se planteó que se tratase de una torre vigía. Un establecimiento en altura de estas características, emplazado estratégicamente en un pequeño repecho bordeado por el río Torres y a medio camino entre las alquerías de L'Alfarella y el Tossal de L'Almisserà, parece vincularse al sistema de defensa y control del territorio (García, Llorens, Pérez, 2003, p. 36). No obstante, el material arqueológico adscrito a esta estructura no permite afirmar que se trate de una torre de alquería pudiendo tratarse de cualquier otra estructura aislada.

\section{FUENTES PARA EL ESTUDIO DEL TERRITORIO DE ALMISSERANS}

\section{1. Fuentes toponímicas}

El uso de la toponimia como fuente para la arqueología en general, y para la arqueología medieval en particular, es una fuente imprescindible y muy valiosa, especialmente si queremos aproximarnos a la percepción de las manifestaciones que han tenido los grupos humanos sobre paisaje.

Esta fuente es imprescindible y muy valiosa, ya que nos permite reconocer la intervención humana sobre el espacio, pues las nomenclaturas hacen alusión al relieve, la orografía, las relaciones comerciales, aprovechamiento del suelo, los tipos de riego, entre muchas otras. No obstante, su utilización ha de ser de forma concienzuda y adecuada, y siempre y cuando no sea la única.

La lengua árabe ha dejado una impronta muy importante en la comarca al respecto de términos asociados al regadío (Barceló, 1982, 23-35; 2010, pp. 45-88; Glick, 1988, p. 229), y éstos nos permiten apreciar aspectos del paisaje andalusí, que no nos proporcionan otras fuentes.

En el caso del territorio que abordamos, al trabajo laborioso que conlleva el análisis propio de los topónimos en sí, se añade la dificultad de tratarse de un territorio que ha sufrido rupturas lingüísticas a lo largo de su historia. Ello conllevó cambios de nomenclaturas de lugares, reutilización de nombres sin concordancia del nombre con el lugar, desplazamientos de topónimos, etc., y ello nos puede acarrear errores de interpretación.

En cuanto a los topónimos referidos a realidades materiales, encontramos:

Alfarella: diminutivo romance del árabe /al-hara/ y significa el barrio (Barceló, 1982, p. 90; Esquerdo y Sais, 1999, p. 26). Antonio Espinosa (Espinosa, 1990, pp. 433-434) habla de que la partida de l'Alfarella se encuentra predominantemente en suelos arcillosos. Estos podrían ser aprovechables para la alfarería.

Almisserans/Almisserà/Almiserà: según Maㅡ Luisa Esquero y Maㅡ Josep Sais (Esquerdo y Sais, 1999, pp. 28-29) proviene del árabe /al-misrâ/, en individual /misr/, y significaría los dos límites. Por otro lado, María D. Cabanes (Cabanes, Ferrer y Herrero, 1981, p. 141) propone que el nombre signifique la frontera entre los valles del actual término de Finestrat y la llanura litoral de la actual ciudad de Villajoyosa y las tierras de Benidorm. Mientras tanto, Asín Palacios establece que el topónimo proviene de la base árabe /al-mis-rad/ y significa el yermo. Francesc Xavier Llorca (Llorca, 2007, p. 201) también expone la problemática si este término significa límite o terreno yermo; no menciona nada al respecto de si significaría huerto o jardín. Argumenta que ante la inexistencia en el árabe hispánico de almiserà en sentido de terreno yermo se debería de interpretar esta palabra como límite. Por otro lado, Carme Barceló (Barceló, 1982, p. 92) propone que este término proviene del árabe / al-munya/ y vendría a significar el huerto o el jardín. Agustí Galiana al respecto de este topónimo establece que se escribe con una -s-, almiserà, y no con dos, pues así aparece en la documentación (Galiana, 2011b, p. 141). 


\section{2. Cartografía y planimetría}

Otras herramientas eficaces son la planimetría y la cartografía. Tanto la cartografía como la planimetría son representaciones del espacio condicionadas por lo que el hombre quiere representar (Torró, 1990, p. 35). Por ello que se traten de fuentes valiosas, pero con limitaciones.

En nuestro caso de estudio, no disponemos de gran cantidad de documentación referida a la zona hasta épocas relativamente recientes. No obstante, contamos con algunas representaciones gráficas del término de Villajoyosa desde el siglo XVIII hasta la aparición de los primeros planos catastrales. En primer lugar, analizamos un plano de 1786 que muestra el término municipal de La Vila ${ }^{10}$. No proporcionó mucha información de nuestro interés, pero facilitó algunos datos al respecto de la consolidación de caminos tradicionales y la organización del parcelario. Posteriormente, se consultó el plano de la Provincia de Alicante realizado por Francisco Coello en 185911, así como se ha accedido a los bosquejos planimétricos realizados por el Instituto Geográfico y Estadístico de $1897^{12}$. Estos contenían valiosa información toponímica, geográfica, redes de comunicación, etc. Ya en el siglo XX, el abanico se amplía. Se dispone del catastro de 1920 de Villajoyosa y de Finestrat ${ }^{13}$. Además de información de la que ya disponíamos por anteriores planos, pudimos observer la parcelación de la partida con gran detalle. Por último, además de la consulta de la Cartografía militar de España. Mapa General, Serie L, E. 1:50.000. Hoja 847, Villajoyosa de 1997 realizada por el Servicio Geográfico del Ejército, se consultó un mapa general del término de La Vila de 2007 con las actuales partidas urbanas y rurales (Galiana, 2007, pp. 122-123).

\section{3. Fotografía aérea}

Por último, otro recurso provechoso para la investigación e interpretación de espacios sociales es la fotografía aérea. Esta principalmente se utiliza con tres objetivos. Por un lado, descubrir yacimientos arqueológicos ${ }^{14}$; por otro, sirve de apoyo en la contextualización de yacimientos en su territorio y de análisis de pautas de territorialidad y, por último, es un recurso útil para ilustrar la extensión y aspecto de yacimientos ya conocidos. No obstante, tiene otros usos, como por ejemplo, el análisis de la red de comunicaciones. Ésta constituye una "armadura" (Torró, 1990, p. 33) del paisaje, de forma que la constatación de una superposición de caminos y parcelarios, desapercibidos desde la superficie, nos puede proporcionar elementos datables cronológicamente que expliquen la evolución del paisaje.

Contamos principalmente con cuatro fotografías aéreas para nuestro caso de estudio. Estas fotografías son las correspondientes al Vuelo Americano de 1956 ${ }^{15}$, los vuelos de 1976 y 1977 de Villajoyosa ${ }^{16}$, a raíz de la construcción de la Autopista AP-7, así como a un vuelo de 1984 del término de

10 Plano que lleva por título Plano que expresa el término de Villajoyosa y término que se disputa de autor anónimo. Fue entregado por el Consejo de Castilla en la disputa entre Alicante y Villajoyosa por sus límites. Fue descubierto por Juan Manuel del Estal en 1983 y se encuentra en el Centro Geográfico del Ejército de Tierra (Galiana, 2012, p. 604).

11 Perteneciente al corpora documental del Atlas de España y sus posesiones en ultramar. Se encuentra inventariado con el no 0556 del Catálogo de Fondos Cartográficos del IGN, publicado en el año 2000.

12 Se encuentran en la cartoteca del Instituto Geográfico Nacional. Se obtuvieron para este trabajo gracias a Pablo Giménez Font, profesor de Geografía Física de la Universidad de Alicante, quién me porporcionó una copia digital.

13 Archivo Histórico Provincial con sede en Alicante.

14 Se trata de una herramienta útil para la prospección en superficie. Es cierto que hoy en día, son otras las herramientas utilizadas con este fin, sin embargo, no deja de ser una herramienta de consulta. Al respecto de los paisajes medievales, difícilmente se puede esperar descubrir restos arqueológicos con esta fuente, sin que ya sean conocidos por otras fuentes (fuentes escritas, toponimia, etc.).

15 1956-1957 Americano, Serie B Fototeca digital, Instituto Geográfico Nacional.

16 Instituto Geográfico Nacional. 


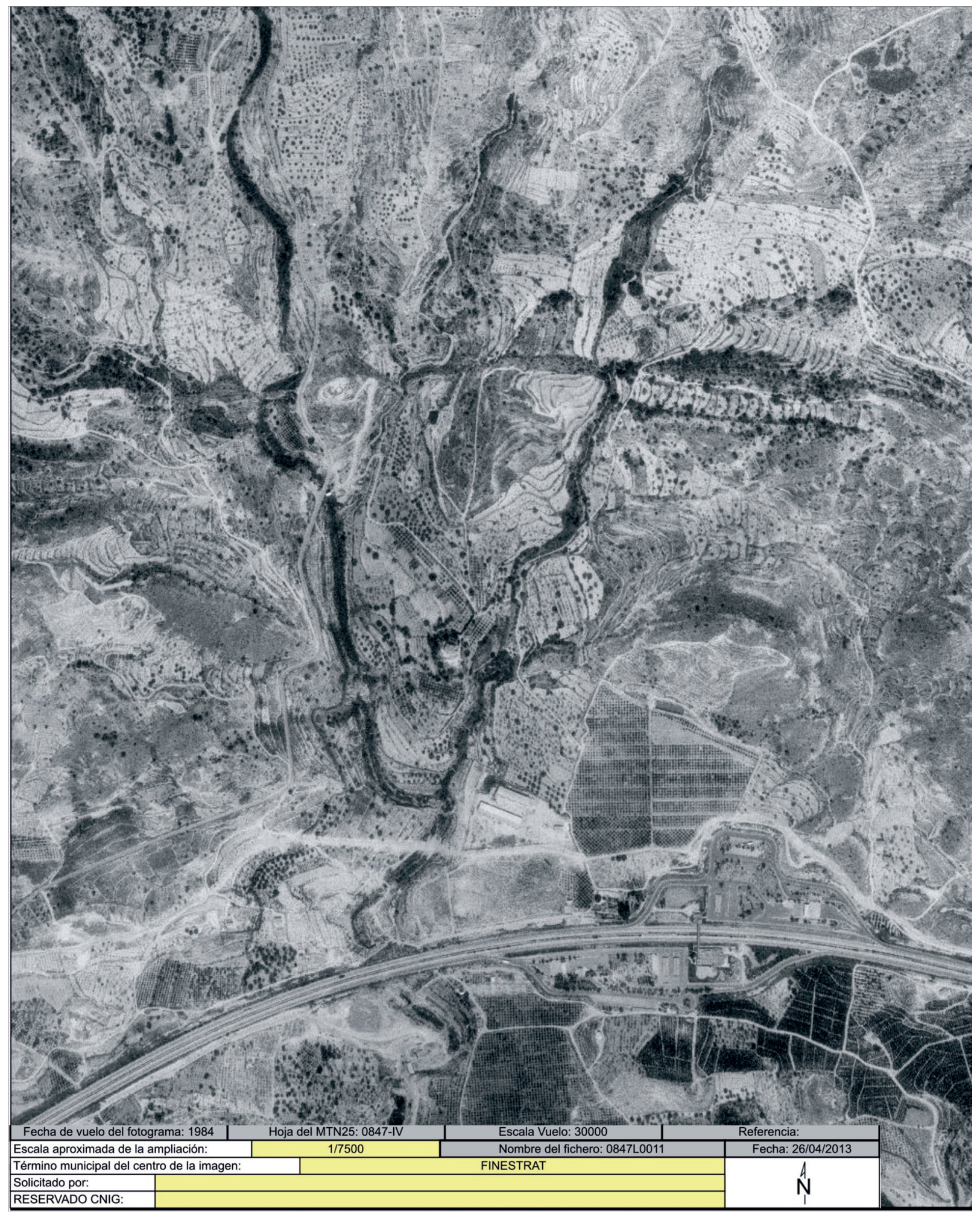

Fig. 7. Vuelo propio de Finestrat de 1984 (Fuente: Instituto Geográfico Nacional).

Finestrat ${ }^{17}$. En estas cuatro imágenes localizamos las diferentes anomalías naturales que presenta el paisaje, como son La Serra d'Orxeta, La Serra Cortina, El Puig Campana, entre otras. De estas montañas se podría intuir que derivarían algunas materias primas y recursos utilizados por las poblaciones

17 Instituto Geográfico Nacional. 
islámicas, como son la madera, alimentos varios, o vegetación arbustiva para la fabricación de objetos muebles, elementos de vestimentas, entre otros usos. Un ejemplo de ello, es la nomenclatura que se observe en uno de los planos citados anteriormente y que hacía alusión al barranco y camino del Murtal. El topónimo hace alusión a una planta utilizada como acción antiséptica y antibiótica, además de ser digestiva, balsámica y ayudar a combatir los procesos inflamatorios.

Otro elemento interesante es la fosilización de dos vías pecuarias, la Vereda Real que limita en algunos tramos el término de Villajoyosa con Finestrat y la vereda del Azagador, en "paralelo" a la vereda real por su parte inferior (Fig. 7). Ante estos datos, debemos plantearnos la relación de la actividad ganadera con estas poblaciones islámicas. Se ha presupuesto que la base económica de este territorio ha sido desde antiguo la actividad agraria, no obstante, a pesar de que la agricultura jugase un papel muy importante no se ha de desestimar a la ligera una importante actividad ganadera, al igual que, por la cercanía de estas poblaciones al mar, de una mínima actividad pesquera.

\section{ANÁLISIS ESPACIAL DEL ÁREA DE L'AMISSERÀ}

Con la aplicación de los Sistemas de Información Geográfica (SIG) en Arqueología podemos obtener una serie de elementos entorno al paisaje que, en conjunto con el apartado anterior, nos permitirá establecer una aproximación agrícola afín a estas alquerías.

\section{1. Dominio espacial y caracterización de los suelos. Cultivo y usos de suelo}

La visibilidad se considera un factor al que la gran mayoría de las sociedades del pasado prestaron atención a la hora de establecer su emplazamiento, así como por el control y defensa del territorio. Para la Arqueología, el estudio del dominio espacial mediante una herramienta SIG ha permitido facilitar la vinculación de un yacimiento con su entorno. No obstante, siempre hay que tener en cuenta que los resultados que se obtienen de estos análisis de visibilidad deben ser tratados como supuestos y nunca como afirmaciones absolutas, pesto que hay variables que no pueden ser cuantificadas con estos análisis. En nuestro caso, los análisis han tenido el fin de observar la visión del conjunto del terrero perceptible desde los enclaves. Del análisis comparativo realizado a los enclaves de mayor envergadura (Fig. 8), parece existir una mayor preocupación por parte de los habitantes de Foietes de controlar las tierras situadas al Sur, mientras que el enclave de L'Almisserà trasladaría dicha preocupación a las tierras del norte.
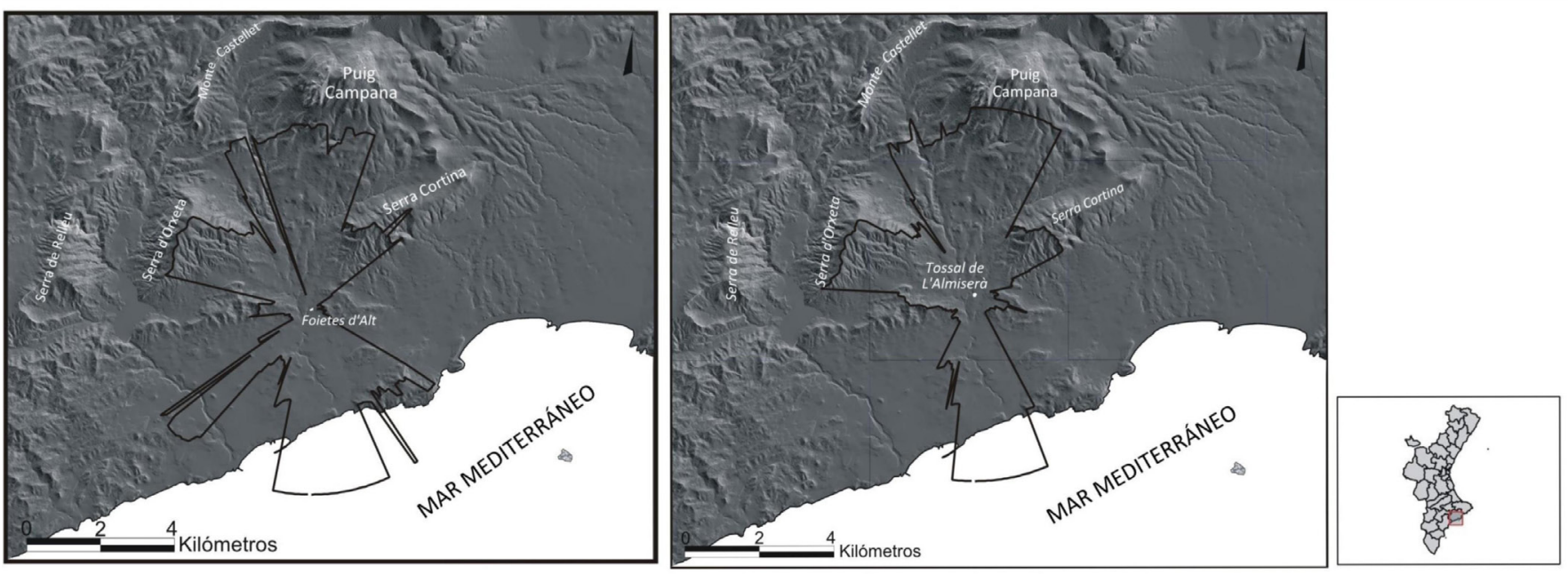

Fig. 8. Mapa comparativo de las visibilidades de Foietes de d'Alty Tossal de L'Almisserà (Fuente: Instituto Cartográfico Valenciano) [Elaboración propia]. 

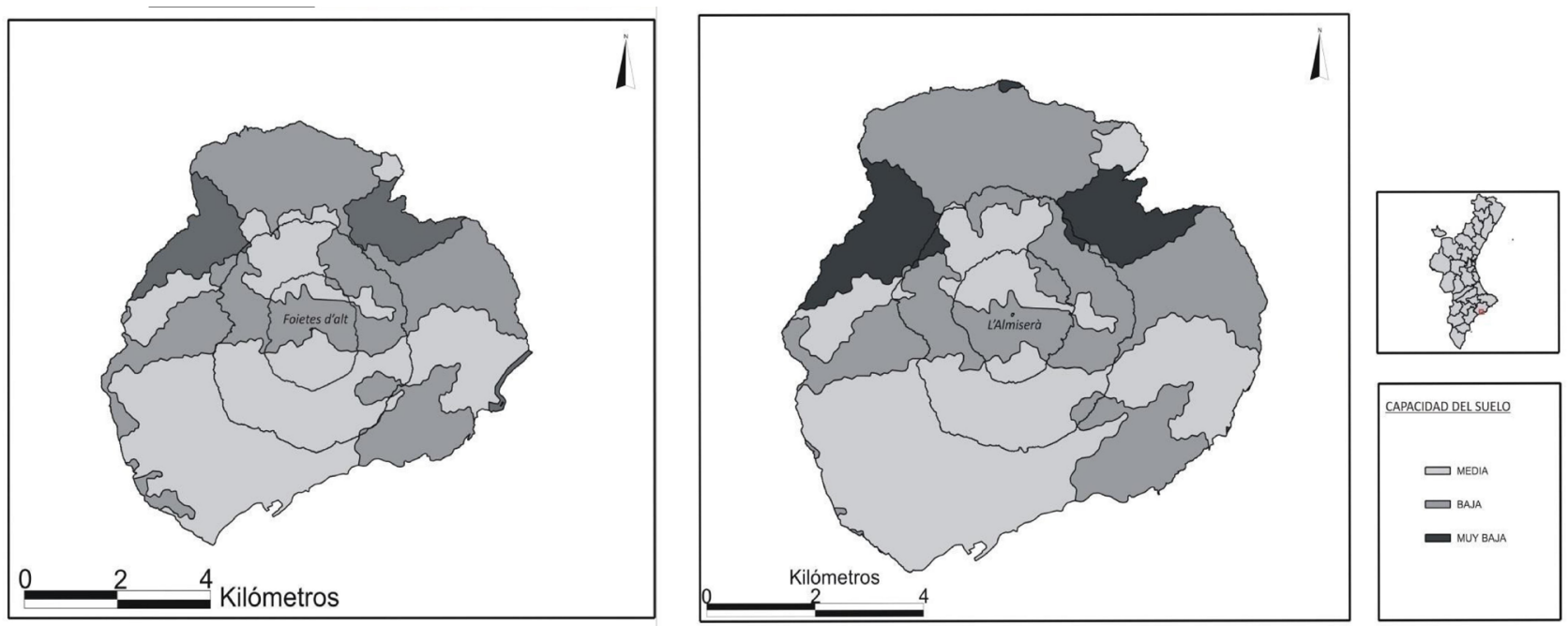

Fig. 9. Mapa comparativo de las capacidades de los suelos de Foietes de d'Alt y Tossal de L'Almisserà con indicación de las isócromas de 15, 30 y 60 minutos (Fuente: Instituto Cartográfico Valenciano) [Elaboración propia].

Esa preocupación por el espacio visual de Foietes al sur, podría hacer alusión al control de las tierras de cultivo ${ }^{18}$. Por la toponimia, la zona circundante hace alusión a tierras de cultivo, mientras que el lugar de establecimiento del enclave parece responder a terrenos de menor calidad, como se puede apreciar en la figura 9. En el caso del Tossal de L'Almisserà, la dinámica de accesibilidad a las tierras idóneas a ser puestas en explotación es similar al caso anterior. En este caso, disponía de mayor terreno cultivable al norte que al sur y, por el volumen reducido de casas localizadas en el asentamiento, cabe la posibilidad de que los terrenos del norte fuesen suficientes para el autoabastecimiento de la alquería.

Al respecto de la visibilidad de la Altalaya (Fig. 10), a pesar de haberse interpretado como un punto de control y defensa, no disfruta de una mayor visibilidad que los enclave anteriores. Ello podría suponer un replanteamiento al respecto de la interpretación del yacimiento. No obstante, cabría barajar la hipótesis de que cumpla la función defensiva ante alquerías como L'Alfarella que no disponían de un buen campo de visión o, quizás, que su control más exhaustivo se dirija al norte para vigilar las vías de paso y entrada al valle.

\section{CONCLUSIONES Y PERSPECTIVAS DE FUTURO}

Como conclusión tras el análisis de toda la documentación, podemos resolver, en primer lugar, que presentamos un panorama parcial y sesgado como consecuencia de la ausencia de información de la comarca y, concretamente, en lo que respecta a nuestra zona de estudio. Los datos recabados no son suficientes para abordar este tipo de estudios sin contemplar la idea de que nos toparemos con vacíos históricos y cuestiones sin respuesta a día de hoy. El problema de este desconocimiento del periodo islámico en estas tierras viene dado como resultado de las escasas fuentes escritas, así como

18 El análisis de los tipos de suelos y el coste por recorrido conllevan una serie de problemas teóricos y metodológicos. Incurrimos en cierto modo al determinismo medioambiental y a parámetros establecidos para fijar las áreas de captación mediante un factor espacio-temporal predefinido actualmente. Tampoco debemos dejar de lado la realidad topográfica, la complicación que supondría circular por éste o el peso corporal del caminante, entre otras variables, pues éstas podrían variar los resultados y la interpretación misma. 

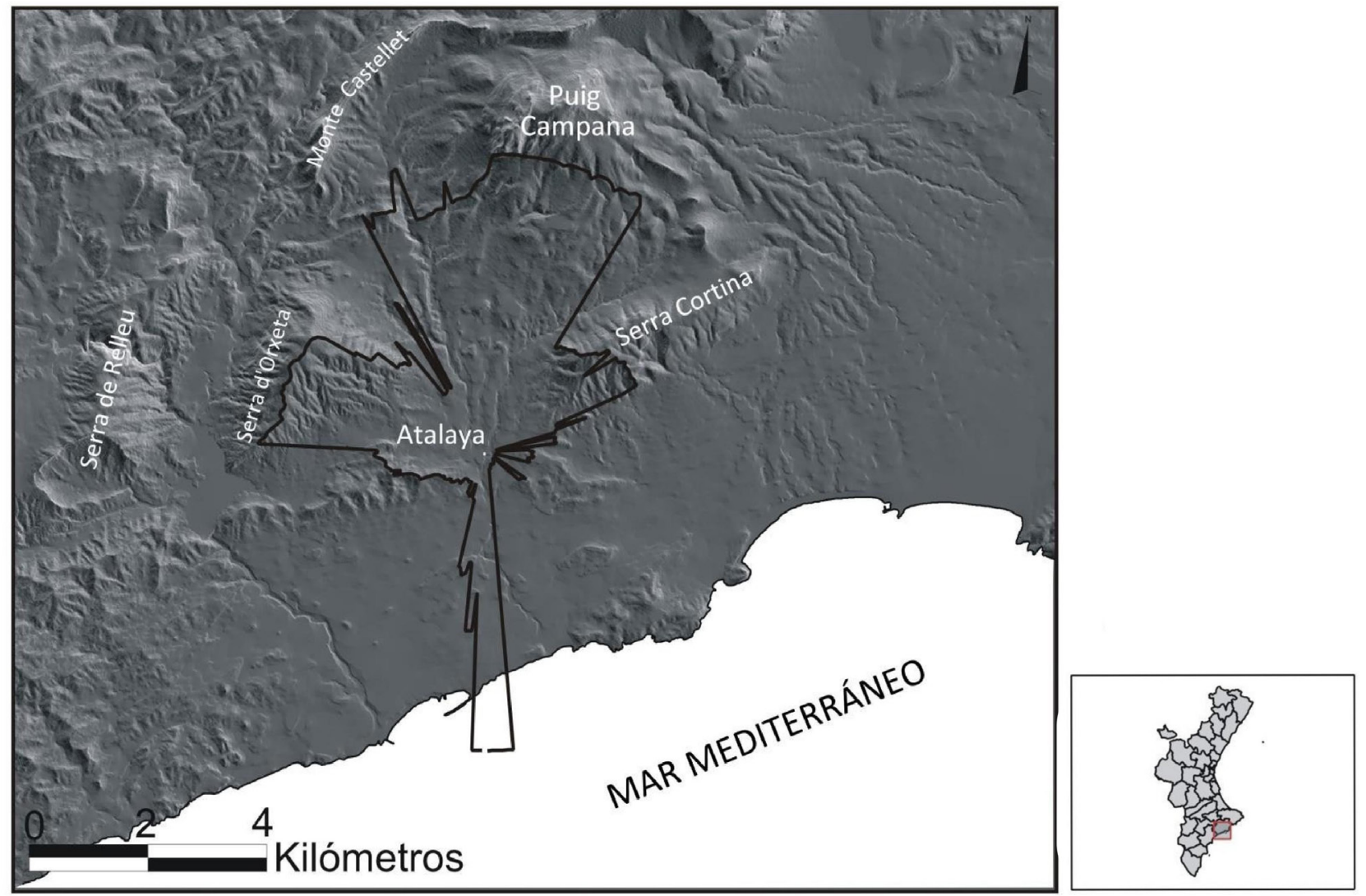

Fig. 10. Mapa de la visibilidad de la Atalaya (Fuente: Instituto Cartográfico Valenciano) [Elaboración propia].

a los insuficientes trabajos científico-arqueológicos. En rigor, estas carencias no son consecuencia del planteamiento y acción por parte de las empresas arqueológicas, autónomos/as y administración pública, sino por el carácter específico de las mismas intervenciones. Por ello, se han aplicado dinámicas de asentamientos similares procedentes de otras zonas del Šarq al-Andalus mejor estudiadas (Angelé y Cressier, 1992; Azuar, 1989, 1999; Azuar y Gutiérrez, 1999; Bazzana, 1985; Bazzana y Guichard, 1976, 1983; Gilotte, 2010; Gutiérrez, 1995, 1996).

Por otro lado, a pesar de las limitaciones, es necesario subrayar la importancia de realizar estos estudios para obtener datos acerca de estas sociedades agrícolas. El estudio independiente de las áreas de residencia no nos ofrece la información necesaria para conocer todos los aspectos relacionados con la interrelación del hombre con el medio físico. No es posible el estudio por separado de las alquerías y, por otro, una lectura del espacio agrario. Este es un error en el que han incurrido algunos investigadores, como fue el grupo de Miquel Barceló, que planteaban la necesidad de crear un protocolo de actuación para estudiar los espacios agrarios, concretamente de maneca exclusiva de las áreas de regadío y los sistemas hidráulicos (Barceló, 1988; Barceló, Kirchner y Navarro, 1996). Investigadores, como Antonio Malpica ha criticado que no es posible llevar a cabo estos estudios independientes, pues "la vida agraria no es sólo cultivo propiamente dicho" (2012, p. 187).

Por todo lo anterior, este trabajo se enfocó desde una óptica ciertamente novedosa para la zona, aunque no por ello inexplorada en otros ámbitos, como fue la aplicación de la metodología de los SIG a la lectura de un paisaje histórico en el marco de un trabajo de master que tiene por objetivo, precisamente, la iniciación en la investigación. Se pretendió aunar el estudio del hábitat y del territorio, en la que el conocimiento exhaustivo del primero facilitaría la compresión del segundo. 
En este caso, se pudo establecer que los espacios agrícolas regados no necesariamente estaban próximos a las áreas de residencia, constatándose la dificultad de documentar dichos espacios originarios en áreas de intensa y continuada explotación agrícola. Futuros trabajos de excavación combinados con la aplicación de técnicas bioarqueológicas y paleobotánicas que excedían nuestro trabajo inicial permitirán profundizar en la caracterización de los espacios agrícolas de este espectacular conjunto de alquerías. Además, será oportuno comprender y explicar los secanos y la ganadería, mucho más evanescentes en la historia de la investigación y en los registros arqueológicos, pues hasta ahora la preocupación casi exclusiva de la investigación se ha centrado en el regadío (Malpica, 2009, pp. 10-12; 2012, pp. 187-193).

En conclusión, nuestro trabajo en el marco de un programa de investigación de master, se planteó para testar las posibilidades metodológicas de la aplicación de técnicas propias de la arqueología del paisaje a un espacio agrario andalusí, en el que, a diferencia de lo que es frecuente, se han documentado no uno sino varios núcleos residenciales. No se pudo abordar el reto planteado en su integridad, pero creemos que esta humilde aportación abre un camino a explorar sobre la base de la identificación de tipologías constructivas rurales y las pautas seguidas en los procesos de agregación rural, para relacionarlos con la construcción del paisaje rural, la estructura social que los concibe y proponer una significación social para dichos modelos.

\section{BIBLIOGRAFÍA}

Angelé, S.; Cressier, P. (1992). Velefique (Almería). Un ejemplo de Mezquita rural en alAndalus. Estudios de Arqueología Medieval en Almería. Almería, pp. 241-264.

Azuar Ruiz, R. (1989). Denia Islámica: Arqueología y poblamiento. Alicante.

Azuar Ruiz, R. (1994). Formación y consolidación de los territorios catastrales en época islámica. Los Hûsûn del Vinalopó (Alicante). Siglos VIII al XI. Fortificaciones y castillos de Alicante: Valles del Vinalopó. Petrer, pp. 67-102.

Azuar Ruiz, R. (1999). El paisaje medieval islámico de las tierras al sur del País Valenciano. Geoarqueologia $i$ quaternari litoral. Memorial Maria Pilar Fumanal. Valencia, pp. 49-59.

Azuar Ruiz, R.; Gutiérrez Lloret, S. (1999). Formación y Transformación de un espacio agrícola islámico en el sur del País Valenciano: el bajo seguro (siglos IX- XIII). Castrum 5. Archéologie des espaces agraries méditerranéens au Moyen Âge, pp. 201-211.

Barceló Perrelló, M. (1988). La arqueología extensiva y el estudio de la creación del espacio rural. Arqueología Medieval en las afueras del medievalismo. Barcelona, pp. 195-274.

Barceló Perrelló, M.; Kirchner Granell, H.; Navarro Romero, C. (1996). El agua que no duerme. Fundamentos de la Arqueología hidráulica andalusí. Granada.

Barceló Torres, C. (1982). Toponímia arábiga del País Valencià. Alqueries i castells. Valencia.

Barceló Torres, C. (2010). Noms aràbics de lloc. Alzira

Bazzana, A (1985). Asentamientos medievales en las sierras del bajo maestrazgo: Monte Marinet y Monte Mollet (Castellón de la plana). I C.A.M.E, Tomo III, del 17 al 19 de abril de 1985 en Huesca. s.l., pp. 147-161.

Bazzana, A. (1990). Maisons rurales du shark al-Andaluz, essai de typologie. La casa Hispanomusulmana: aportaciones de la Arqueología. Granada, pp. 247-268.

Bazzana, A. (1992). Maisons d'Al-Andalus, habitat médiéval et structures de peuplement dans l'Espagne Orientale. Madrid. 
Bazzana, A.; Guichard, P. (1976). Recherche sur les habitats musulmans du levant espagnol. Atti del colloquio internazionale di Archeologia Medievale (Palermo- Erice, 20-22 settembre 1974), vol. 1. Palermo, pp. 59- 100.

Bazzana, A.; Guichard, P. (1983). Habitats et sites defensifs d'époque médiévale: Elements d'une recherche dans la région valencienne. Estudis Castellonencs, 1, pp. 611- 696.

Cabanes Pecourt, M.D.; Ferrer Navarro, R.; Herrero Alonso, A. (1981). Documentos y datos para un estudio toponímico de la región valenciana. Valencia.

Calvo Capilla, S. (2014). Las mezquitas de alAndalus. Almería.

Espinosa Ruiz, A. (1987). Catalogación de los fondos arqueológicos del museo etnográfico e histórico de la Vila Joiosa. Carta arqueológica de su término municipal. Alicante.

Espinosa Ruiz, A. (1990). Arqueología Romana de la Vila Joiosa (Tesis doctoral inédita).

Espinosa Ruiz, A. (2011). El patrimoni medieval i modern de la Vila Joiosa. La Vila Joiosa, Arqueología i Museu. Museos municipales en el MARQ. Alicante, pp. 214-221.

Esquerdo Vaello, Ma․ L.; Sais Devesa, Mํㅡ J. (1999). Aproximació a la toponímia Vilera. Villajoyosa.

Galiana Soriano, A. (2001). Història natural de la Marina Baixa. San Vicente del Raspeig (Alicante).

Galiana Soriano, A. (2007). Les partides de la Vila. Revista de Festes de Santa Marta, pp. 122123.

Galiana Soriano, A. (2011a). El medi ambiente en la Marina Baixa. La Vila Joiosa, Arqueología $i$ Museu. Museos municipales en el MARQ. Alicante, pp. 50-67.

Galiana Soriano, A. (2011b). Toponimia medieval de la Marina Baixa. $V$ jornada d'Onomàstica del'AVL, pp. 131- 142.
Galiana Soriano, A. (2012). Documentació histórica i bibliografía de la Marina Baixa. Villajoyosa.

García Gandía, J.R. (2003). Torres, castillos y alquerías. Una aproximación al poblamiento rural islámico en la Marina Baixa. Boletín de Información Municipal de Finestrat, 35, pp. 25-27.

García Gandía, J.R. et al. (2001). Proyecto L'Almisserà. Prospecciones arqueológicas en el término municipal de la Vila Joiosa (Alicante). Recerques del Museo d'Alcoi, 10, pp.125-134.

García Gandía, J.R.; Llorens Campello, S.; Pérez Botí, G (2003). Memoria partida de L'Almisserà (Villajoyosa, Alicante). Inédita.

García Gandía, J.R.; Llorens Campello, S.; Pérez Botí, G. (2004). L'Almisserà: Territorio castral y espacio rural en época islámica. II Jornadas de Arqueología Medieval. De la Medina a la Vila, Petrer-Novelda, 3 al 5 de octubre de 2003. Alicante, pp. 83-105.

García Gandía, J.R.; Llorens Campello, S.; Pérez Botí, G. (2005). L'Almisserà: Territorio castral y espacio rural en época islámica. 1as Jornadas sobre la Actualidad del Patrimonio Arqueológico y Etnográfico de la Marina Baixa. Elche, pp. 9-15.

Gilotte, S. (2010). Aux marges d'al-Andalus. Peuplement et habitat en Estrémadure centreorientale (VIIIe-XIIIe siècles). Helsinki.

Glick, T.F. (1988). Regadío y sociedad en la Valencia medieval. Valencia.

Guichard, P. (2001). Al-Andalus frente a la conquista cristiana. Los musulmanes de Valencia (siglos XI-XIII). Madrid-Valencia.

Gutiérrez Lloret, S. (1995). El origen de la huerta de Orihuela entre los siglos VII y XI: una propuesta arqueológica sobre la explotación de las zonas húmedas del Bajo Segura. Arbor, pp. 65-94.

Gutiérrez Lloret, S. (1996). La Cora de Tudmir. De la antigüedad tardía al mundo islámico. Poblamiento y cultura material. Madrid- Alicante. 
Gutiérrez Lloret, S. (2004). La formación de alAndalus en las tierras meridionales valencianas. II Jornadas de Arqueología Medieval. De la Medina a la Vila, Petrer-Novelda, 3 al 5 de octubre de 2003. Alicante, pp. 17-32.

Gutiérrez Lloret, S. (2007). La islamización de Tudmir: balance y perspectivas. Villa II. Villes et campagnes de Tarraconaise et d'al-Andalus (VIeXIe siècles): la transition. Toulouse, pp. 275-318.

Gutiérrez Lloret, S. (2011). El Reconocimiento arqueológico de la islamización. Una mirada desde al-Andalus. Zona arqueológica, 15: 711, Arqueologia e historia entre dos mundos. Madrid, pp. 191-210.

Gutiérrez Lloret, S. (2012a). Gramática de la casa. Perspectivas de análisis arqueológico de los espacios domésticos medievales en la Península Ibérica (siglos VII-XIII). Arqueología de la Arquitectura. 9, pp. 139-164.

Gutiérrez Lloret, S. (2012b). La arqueología en la historia del temprano al-Andalus: espacios sociales, cerámica e islamización. Villa IV. Histoire et archéologie de l'occident musulman (VIIe-XVe): al-Andalus, Maghreb, Sicile. Toulouse, pp. 33-66.

Gutiérrez Lloret, S. (2015). Casa y casas: Reflexiones arqueológicas sobre la lectura social del espacio doméstico medieval. La casa medieval en la Península Ibérica. Madrid, pp. 17-48.

Llorca Ibi F. X. (2007). Toponimia de la Marina Baixa. Patrimoni, aigua i clima a la marina baixa. Actes de les 2es jornades de patrimonio natural $i$ cultural de la Marina Baixa. Villajoyosa, pp. 199206.

Madoz Ibánez, P. (1845). Diccionario geográficoestadístico-histórico de España y sus posesiones de Ultramar, Tomo XVI. Madrid.

Malpica Cuello, A. (2009). Una propuesta de análisis de la arqueología del paisaje. Un caso concreto de aplicación. Tudmir. Revista del Museo de Santa Clara, 1, pp. 9-29.

Malpica Cuello, A. (2012). Critica de libros: Por una arqueología agraria. Perspectivas de investigación sobre espacios de cultivo en las sociedades medievales hispánicas. Historia Agraria, 58, pp. 185-193.

Ministerio de Agricultura (1981). Ministerio de Agricultura. Evaluación de recursos agrarios. Mapa de cultivos y aprovechamientos, Villajoyosa (Alicante). Madrid.

Torró i Abad, J. (1990). Poblament i espai rural. Transformacions históriques. Valencia. 